\title{
Assessment of transition readiness in adolescents and young adults with chronic health conditions
}

\author{
Paul T. Jensen 1,2, Gabrielle V. Paul ${ }^{2}$, Stephanie LaCount ${ }^{1,2}$, Juan Peng ${ }^{3}$, Charles H. Spencer ${ }^{1,2}$, Gloria C. Higgins ${ }^{1,2}$, \\ Brendan Boyle ${ }^{1,2}$, Manmohan Kamboj ${ }^{1,2}$, Christopher Smallwood ${ }^{1,2}$ and Stacy P. Ardoin ${ }^{1,2^{*}}$
}

\begin{abstract}
Background: Transition from pediatric to adult health care is a vulnerable period for adolescents and young adults. Challenges include paucity of validated measures to assess patients' transition readiness. We evaluated the Transition Readiness Assessment Questionnaire (TRAQ) in adolescents and young adults with rheumatic, gastrointestinal, and endocrine disorders. We examined whether baseline TRAQ scores and other demographic variables predicted transition to adult care over a three year follow up period.

Methods: In this descriptive study at a single institution, eighty-nine adolescents at a single pediatric academic medical center completed demographic and medical history surveys and the TRAQ and were followed over 3 years by telephone interview to determine whether they had transitioned to adult subspecialty care. Transition was defined as attending at least one adult subspecialty appointment. Multivariable logistic regression and Cox proportional hazards regression models were used to determine whether TRAQ scores predicted time to transition.

Results: Of the participants, 56\% had rheumatic, 21\% endocrine, and 23\% gastrointestinal conditions. The TRAQ self-management domain score was not significantly associated with age, gender, socioeconomic status, or specialty. The TRAQ self-advocacy score increased with age. Baseline TRAQ scores did not predict transition or time to transition over three years.

Conclusion: In this cohort of adolescents and young adults who were 16 to 23 years of age at enrollment, $48 \%$ transitioned to adult care over three years of follow up. Nearly half reported not discussing transition with provider or seeing provider independently for part of visit. Older age but not other demographic variables nor baseline TRAQ score predicted transition or time to transition to an adult subspecialty provider; however, a there was a trend towards shorter time to transition with the highest quartile TRAQ scores.
\end{abstract}

Keywords: Adolescent, Young adult, Adult, Transition readiness, Chronic health conditions

\section{Background}

In the United States, approximately 500,000 adolescents with special health care needs reach the age of 18 each year and ultimately need to transition from pediatric to adult health care [1]. The transition from pediatric care to adult care is often a challenging time for patients

\footnotetext{
* Correspondence: stacy.ardoin@osumc.edu;

stacy.ardoin@nationwidechildrens.org

'Division of Rheumatology, Nationwide Children's Hospital, 700 Children's

Drive, Columbus, $\mathrm{OH} 43205$, USA

${ }^{2}$ The Ohio State University College of Medicine, 370 W. 9th Avenue,

Columbus, $\mathrm{OH} 43210$, USA

Full list of author information is available at the end of the article
}

with chronic medical conditions and their providers [2]. Many adolescents and young adults lack important self-management and health care utilization skills [3-5] and are insufficiently prepared to move to adult care $[6,7] . G a p s$ in health care can lead to increased morbidity and mortality [8-14].

A transition process which starts in early adolescence can help patients develop self-care, self-advocacy, and decision-making skills, and the need for such a process has been acknowledged [15]. However, despite several efforts to improve the transition process, gaps remain. The 2001 National Survey of Children with Special 
Health Care Needs (NS-CSHCN) found that only 15\% of youth reported that their doctor had discussed changing needs in adulthood, including the need to transition to an adult doctor [16]. A 2006 follow up NS-CSHCN survey identified that only $40 \%$ of youth reported meeting the medical transition outcome measure (a composite of whether the provider had discussed transition to adult care, health care needs, health insurance, and had encouraged the patient to take responsibility for his/her own care) $[1,6]$. A 2014 systematic review concluded that most published studies aiming to improve transition process failed to address the "triple aim" of impact on health outcomes, patient satisfaction, and cost [17]. The Agency for Health Care Research and Quality (AHRQ) has acknowledged that identification of optimal transition processes and interventions are limited by the lack of a robust evidence base [18].

In 2002, the American Academy of Pediatrics (AAP), American Association of Family Physicians (AAFP) and American College of Physicians-American Society of Internal Medicine (ACP) jointly recommended that providers regularly assess transition readiness skills using an objective measure [15]. Recently, new tools have been developed to measure patients' readiness to transition to adult care [19-21]. The Transition Readiness Assessment Questionnaire (TRAQ), developed by Sawicki and colleagues, is one of these tools.

The TRAQ was initially studied at the Jacksonville Health and Transition Services Clinic at the University of Florida in Jacksonville in a cohort of patients with several pediatric-onset chronic health conditions including spina bifida, cerebral palsy, diabetes mellitus, cystic fibrosis, sickle cell disease, seizure disorders, and autism as well as in patients attending the Cystic Fibrosis Center at Boston Children's Hospital. In the initial study, TRAQ self-management (Domain 1 ) and self-advocacy (Domain 2) scores were positively associated with age and the TRAQ selfadvocacy score was higher in females [22]. Patient education interventions can improve TRAQ scores as shown in studies of patients with heart disease and cystic fibrosis [23, 24]. A revised 20-item TRAQ questionnaire (TRAQ 5.0) found no significant association between TRAQ scores and race, ethnicity, or insurance types [3]. The TRAQ is one of the few available validated, patient-reported, disease nonspecific transition readiness tools [25].

In this study, we aimed to evaluate whether demographic variables or baseline TRAQ scores predicted transition or time to transition over 3 years in a cohort of adolescents and young adults with rheumatic, endocrine, and gastrointestinal (GI) disorders.

\section{Methods}

\section{Patient population}

Institutional Review Board approval was obtained for this study, and informed consent was obtained for all participants. Consecutive patients with rheumatologic, endocrine and GI chronic diseases expected to require adult subspecialty care were included and followed for three years from 2011 to 2015. All participants were recruited from outpatient pediatric specialty clinics at standard of care clinic visits. At the time of the study, none of the involved clinics had a formal transition policy or process. Participants had to be English speaking, aged 16 to 25 years, and able to complete the TRAQ instrument.

\section{Study design}

This is a descriptive, longitudinal study performed at a single academic institution. At the baseline visit, participants completed demographic and medical history questionnaires. Medical history was confirmed by chart review. Participants then completed the TRAQ version 4.1. Providers were blinded to TRAQ scores. After the baseline visit, study personnel contacted participants every 6 months over a three year period by telephone interview. Study personnel inquired whether participants had been seen by an adult subspecialty provider. Attendance at the adult subspecialty provider visit was confirmed by chart review or having the adult providers document study participant clinic attendance.

\section{TRAQ instrument}

The TRAQ 4.1 is a 29-item patient-reported measure of transition readiness across two domains: self-management (Domain 1) and self-advocacy (Domain 2) [22]. Items included in the TRAQ 4.1 are listed in Table 1. Answers are reported on a 1 to 5 scale based on the Stages of Change Model ranging from "I do not need to do this" to "I always do this when I need to." A sixth option of "Not needed for my care" was also allowed for questions not applicable to an individual patient. Within each domain, the responses to each item were averaged to produce a domain score ranging from 1 to 5 . The TRAQ is not specific to any diagnosis or specialty [22].

\section{Statistical analysis}

Baseline demographic and transition-related characteristics were compared across groups by using t-tests and chi-square tests as appropriate. Univariate logistic regression models were used to test the effect of potential predictors on transition. Odds ratios describing the odds of transition and 95\% confidence intervals were estimated from these univariate logistic regression models. Variables with $p$-value $<0.15$ in the univariate logistic regression model were entered into multivariate models. 
Table 1 Items Included in the Transition Readiness Assessment Questionnaire, version $4.1^{\text {a }}$

\author{
Domain 1: Skills for Chronic Condition Self-Management \\ Do you fill a prescription if you need to? \\ Do you know what to do if you are having a bad reaction to your \\ medications? \\ Do you pay or arrange payments for your medications? \\ Do you take medications correctly and on your own? \\ Do you reorder medications before they run out? \\ Do you call the suppliers when there is a problem with the \\ equipment? \\ Do you order medical equipment before they run out? \\ Do you arrange payment for the medical equipment and \\ supplies? \\ Do you call the doctor's office to make an appointment? \\ Do you call the doctor about unusual changes in your health? \\ Do you apply for health insurance if you lose your current \\ coverage? \\ Do you know what your health insurance covers?
}

Do you manage your money and budget household expenses?

Do you reorder medications before they run out?
Domain 2: Skills for Self-Advocacy and Health Care Utilization

Do you fill out the medical history form, including a list of your allergies?

Do you keep a calendar or list of medical and other appointments?

Do you tell the doctor or nurse what you are feeling?

Do you ask questions of the doctor, nurse or clinic staff?

Do you make a list of questions before the doctor's visit?

Do you request the accommodations \& support you need at school or work?

Do you apply for a job or work or vocational services?

Do you get financial help with school or work?

Do you help plan or prepare meals/food?

Do you help keep home/room clean or clean up after meals?

Do you use neighborhood stores and services?

Do you use community support services or advocacy services when you need them?

aRespondents select one of the following answers for each item: "Not needed for my care," "No, I do not know how," "No, I do not know how but I want to learn," "No, but I am learning to do this," "Yes, I have started doing this," or "Yes, I always do this when I need to"

Cox proportional hazards regression models were used to examine the effect of TRAQ Domain 1 score and TRAQ Domain 2 score on the "hazard" function of transition after entering the study, while controlling for patient's age at enrollment. A two-sided significance level of $\alpha=0.05$ was used for all tests. Analyses were performed by using SAS version 9.3 (SAS Institute, Cary, NC).

\section{Results}

\section{Baseline characteristics}

As outlined in Table 2, the 89 participants were $65 \%$ female, $81 \%$ Caucasian, $97 \%$ non-Hispanic. The mean age at enrollment was 18.2 years $(58 \%$ were $16-18$ years; $37 \%$ were $19-21$ years, and 5\% were $22-23$ years at baseline). Fifty-six percent of the participants had a rheumatic condition (of these, 58\% had inflammatory arthritis; 24\% had lupus, Sjogren's syndrome or mixed connective tissue disease; $12 \%$ had vasculitis and $6 \%$ had other conditions), An endocrinologic condition was the primary diagnosis in $21 \%$ (of these, $60 \%$ had diabetes, $10 \%$ had polycystic ovarian syndrome, $10 \%$ had pituitary dwarfism, and the remainder had Cushing's syndrome, Klinefelter's syndrome or hyperprolactinemia), A gastrointestinal disorder was present in and $23 \%$, and all but one had inflammatory bowel disease. Ninety-six percent were unmarried and $82 \%$ reported living with parents. Just over half of the patients (53\%) were not employed, and $81 \%$ were in school at time of enrollment. The majority of patients had private insurance supplied by their parents (65\%).

Only $40 \%$ of participants reported having discussed transition to adult care with their pediatric subspecialty provider. When asked if they saw their subspecialty provider independently for at least part of the visit, 33\% reported never seeing the provider independently; $16 \%$, rarely; $18 \%$, sometimes; $25 \%$ often; and $7 \%$, always.

\section{Baseline TRAQ scores}

Baseline TRAQ domain 1 scores were not significantly related to age groups, gender, race, or disease specialty (all $P$-values $>0.05$.) TRAQ domain 2 scores were significantly increased in older age groups $(P$-value $=0.02)$, but were not different based on gender, race, or disease specialty (all $P$-values $>0.05$ ).

\section{Transition follow up}

Of the 89 participants, 39 transitioned to adult care, 44 did not transition, and transition status could not be determined for 6 participants. Baseline characteristics were similar between the transitioned and nottransitioned groups (Table 2). In univariate logistic regression analyses (Table 3), with each one-year increase in patient's age, we noted an approximately $39 \%$ increase (OR 1.39, 95\% CI 1.04-1.86; P-value: 0.028 ) in the odds of transition. Participants who had discussed transition with their provider at baseline 
Table 2 Baseline Characteristics of Cohort

\begin{tabular}{|c|c|c|c|c|}
\hline & Overall $(N=89)$ & Transitioned $(N=39)$ & Non-transitioned $(N=44)$ & $P$-value \\
\hline Age, mean (SD), year & $18.3(1.6)$ & $18.8(1.6)$ & $18.0(1.5)$ & 0.03 \\
\hline Gender, No., \% & & & & 0.54 \\
\hline Female & $59(66 \%)$ & $14(36 \%)$ & $13(30 \%)$ & \\
\hline Male & $30(34 \%)$ & $25(64 \%)$ & $31(70 \%)$ & \\
\hline Ethnicity, No., \% & & & & 0.59 \\
\hline White & $72(81 \%)$ & $31(79 \%)$ & 37 (84\%) & \\
\hline Non-white & $17(19 \%)$ & $8(21 \%)$ & $7(16 \%)$ & \\
\hline Household income, No., \% & & & & 0.43 \\
\hline$<\$ 25,000$ & $11(13 \%)$ & $4(10 \%)$ & $7(16 \%)$ & \\
\hline$\$ 25,000-\$ 45,999$ & $16(18 \%)$ & $5(13 \%)$ & $9(21 \%)$ & \\
\hline$\$ 50,000-\$ 74,999$ & $13(15 \%)$ & $5(13 \%)$ & $8(19 \%)$ & \\
\hline$\$ 75,000-\$ 99,999$ & $6(7 \%)$ & $2(5 \%)$ & $4(9 \%)$ & \\
\hline$\$ 100,000-\$ 150,000$ & $8(9 \%)$ & $4(10 \%)$ & $4(9 \%)$ & \\
\hline$>\$ 150,000$ & $7(8 \%)$ & $4(10 \%)$ & $1(2 \%)$ & \\
\hline Unknown & $27(31 \%)$ & $15(38 \%)$ & $10(23 \%)$ & \\
\hline Type of insurance, No., \% & & & & 0.44 \\
\hline Public & $22(26 \%)$ & $8(22 \%)$ & $12(29 \%)$ & \\
\hline Private & $62(74 \%)$ & $29(78 \%)$ & $29(71 \%)$ & \\
\hline Specialty, No., \% & & & & 0.16 \\
\hline Rheumatology & $50(56 \%)$ & 19 (49\%) & $28(64 \%)$ & \\
\hline Endocrinology & $19(21 \%)$ & $8(21 \%)$ & $10(23 \%)$ & \\
\hline Gastroenterology & $20(23 \%)$ & $12(31 \%)$ & $6(14 \%)$ & \\
\hline TRAQ domain 1 score, mean (SD) & $3.1(1.0)$ & $3.2(1.0)$ & $3.0(0.8)$ & 0.37 \\
\hline TRAQ domain 2 score, mean (SD) & $3.7(0.7)$ & $3.9(0.5)$ & $3.7(0.9)$ & 0.21 \\
\hline Duration of disease, mean (SD), year & $4.8(3.9)$ & $5.2(3.9)$ & $4.5(4.0)$ & 0.27 \\
\hline Have discussed transition with provider, No., \% & $35(41 \%)$ & $21(54 \%)$ & $13(33 \%)$ & 0.06 \\
\hline Have seen provider independently, No., \% & & & & 0.22 \\
\hline Always/Often/Sometimes & $44(51 \%)$ & $23(59 \%)$ & $19(45 \%)$ & \\
\hline Never/Rarely & $43(49 \%)$ & $16(41 \%)$ & $23(55 \%)$ & \\
\hline
\end{tabular}

Abbreviations: TRAQ Transition Readiness Assessment Questionnaire

had a 142\% increase (OR 2.42; 95\% CI: 0.97-6.04; $P$-value 0.058$)$ in the odds of transition at the end of the study compared to those who did not have such a discussion. In the multivariable model with TRAQ Domain 2 (self -advocacy) score, age, and whether participant had discussed transition with the provider, none of the effects were significantly related to transition at the end of the study.

The time from study entry to the date of first visit with the adult provider was also analyzed in a multivariable Cox proportional hazards model with baseline TRAQ scores and age. (Fig. 1) The baseline TRAQ scores did not predict time to transition, though as noted in fig. 1, there was a possible trend showing sooner time to transition with higher TRAQ scores (all $P$-values $>.05$ ).

\section{Discussion}

Because transition from pediatric to adult care is a vulnerable and risky time, there is significant impetus to improve transition processes and outcomes $[2,26]$. The 2002 consensus guidelines proposed by the American Academy of Pediatrics, American College of Physicians and American Academy of Family Physicians-American Society of Internal Medicine called for transition to adult care to be a gradual process with a written, annually updated transition plan starting at age $14[6,15]$. Subsequent guidelines published in 2011 recommend that transfer to adult provider occur between the ages of 18 and 21 [1].

As part of developing more reliable transition processes, these guidelines recommended that providers 
Table 3 Multivariable Analysis of Relationships between Baseline Characteristics and Transition

\begin{tabular}{|c|c|c|c|c|c|c|}
\hline \multirow[t]{2}{*}{ Predictor } & \multirow[t]{2}{*}{ Levels } & \multicolumn{2}{|l|}{ Transition } & \multirow[t]{2}{*}{ OR } & \multirow[t]{2}{*}{$95 \% \mathrm{Cl}$} & \multirow{2}{*}{$\begin{array}{l}P \text { - } \\
\text { value }\end{array}$} \\
\hline & & Yes & No & & & \\
\hline TRAQ domain 1 score & One unit increase & $3.22 \pm 0.97$ & $3.03 \pm 0.83$ & 1.28 & $0.79-2.10$ & 0.32 \\
\hline TRAQ domain 2 score & One unit increase & $3.90 \pm 0.53$ & $3.65 \pm 0.86$ & 1.67 & $0.85-3.27$ & 0.14 \\
\hline Age (years) & One unit increase & $18.77 \pm 1.65$ & $17.98 \pm 1.49$ & 1.39 & $1.04-1.86$ & 0.03 \\
\hline Disease duration (years) & One unit increase & $5.21 \pm 3.85$ & $4.50 \pm 4.04$ & 1.05 & $0.94-1.17$ & 0.42 \\
\hline \multirow[t]{2}{*}{ Gender } & Female $(N=56)$ & $25(45 \%)$ & $31(55 \%)$ & 0.75 & $0.30-1.88$ & 0.54 \\
\hline & Male $(N=27)$ & $14(52 \%)$ & $13(48 \%)$ & 1.0 & & \\
\hline \multirow[t]{2}{*}{ Race } & White $(N=68)$ & $31(46 \%)$ & 37 (54\%) & 0.73 & $0.24-2.25$ & 0.59 \\
\hline & Non-white $(N=15)$ & $8(53 \%)$ & $7(47 \%)$ & 1.0 & & \\
\hline \multirow[t]{2}{*}{ Insurance type } & Private $(N=58)$ & $29(50 \%)$ & $29(50 \%)$ & 1.5 & $0.53-4.21$ & 0.44 \\
\hline & Public $(N=20)$ & $8(40 \%)$ & $12(60 \%)$ & 1.0 & & \\
\hline \multirow[t]{3}{*}{ Specialty } & Endocrinology $(N=18)$ & $8(44 \%)$ & $10(56 \%)$ & 1.18 & $0.39-3.53$ & 0.16 \\
\hline & Gastroenterology $(N=18)$ & $12(67 \%)$ & $6(33 \%)$ & 2.95 & $0.94-9.22$ & \\
\hline & Rheumatology $(N=47)$ & $19(40 \%)$ & $28(60 \%)$ & 1.0 & & \\
\hline \multirow[t]{2}{*}{ Have seen provider independently } & Sometimes/Often/Always ( $N=42)$ & $23(55 \%)$ & $19(45 \%)$ & 1.74 & $0.72-4.20$ & 0.22 \\
\hline & Never/Rarely $(N=39)$ & $16(41 \%)$ & $23(59 \%)$ & 1.0 & & \\
\hline \multirow[t]{2}{*}{ Have discussed transition with provider } & Yes $(N=34)$ & $21(62 \%)$ & $13(38 \%)$ & 2.42 & $0.97-6.04$ & 0.06 \\
\hline & No $(N=45)$ & $18(40 \%)$ & $27(60 \%)$ & 1.0 & & \\
\hline
\end{tabular}

Abbreviations: TRAQ Transition Readiness Assessment Questionnaire

regularly assess transition readiness using an objective measure such as the TRAQ [15]. Assessment of transition readiness allows providers and patients to identify and nurture self-management abilities [27]. In addition to the TRAQ, other transition readiness tools include the UNC TRxANSITION scale [20], the AM I ON TRAC questionnaire [28], and the National Health Care Transition Center GotTransition assessment scale [29].
Some disease specific transition readiness assessment instruments have also been developed, including the Readiness for Adult Care in Rheumatology (RACER) [30], and the Diabetes Knowledge questionnaire [31].

This study reinforces existing data showing that adolescents and young adults are often not prepared for transition. In this cohort of 16 to 25 year olds, fewer than half reported ever having discussed transition to

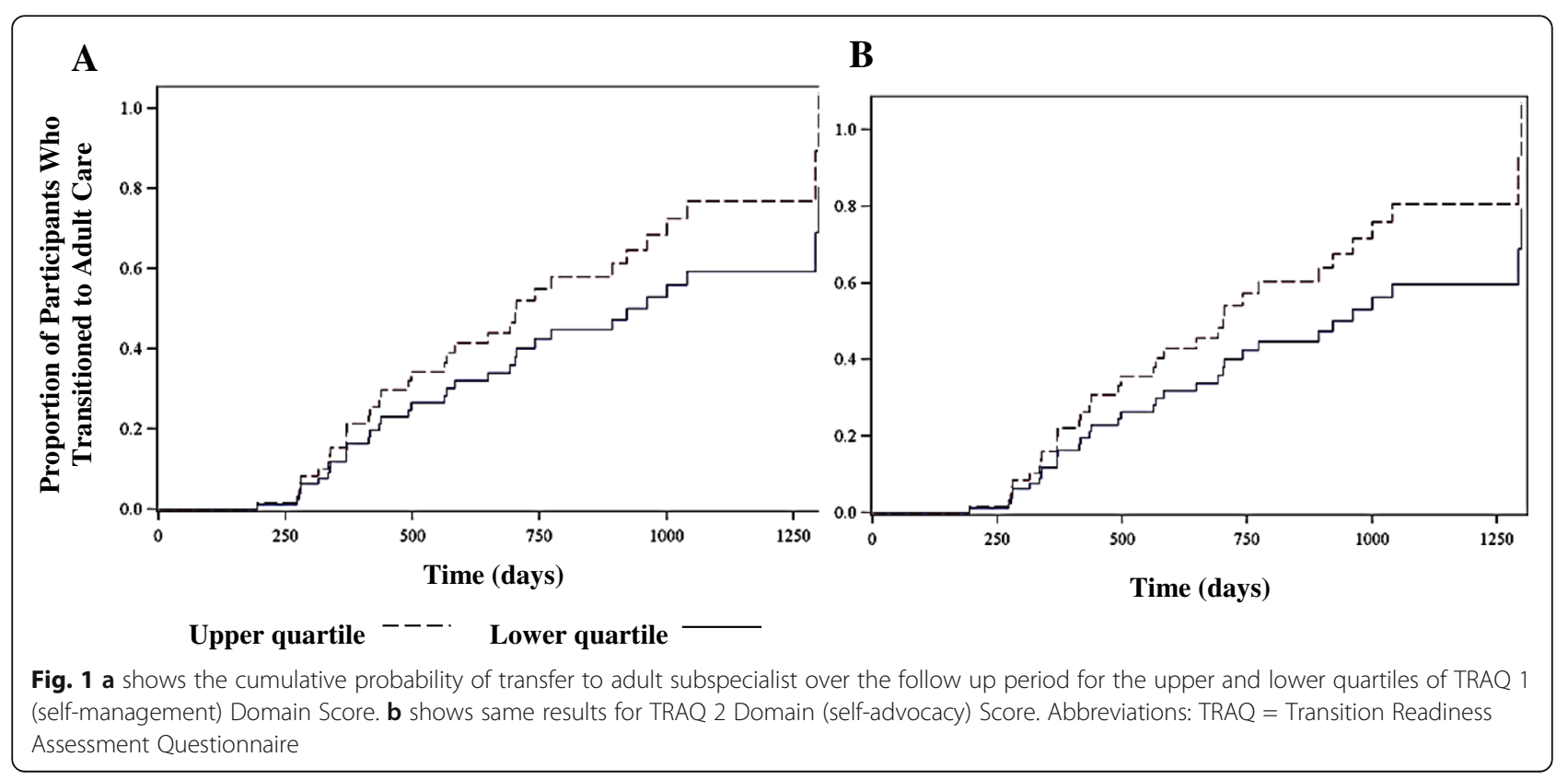


adult provider with their current subspecialty provider. Additionally, almost half (46\%) either never or rarely saw the pediatric provider independently for part of the visit, although the AAP/AAFP/ACP guidelines recommend that adolescents begin seeing providers independently for at least part of the visit at age 14 [1].

To our knowledge, this is the first study to link transition readiness scores to transition outcomes. In our study, age was the only baseline variable that independently predicted transition over 3 years of follow up. In line with previous studies, TRAQ Domain 2 (self-advocacy) scores increased with age. However, in contrast with previous studies, selfadvocacy scores did not differ significantly by gender [22]. The mean TRAQ Domain 1 (self-management) score was 3.1, reflecting the preparation stage of the Stages of Change Model [22]. The mean TRAQ Domain 2 (self-advocacy) score was higher at 3.9, moving toward the action stage. Neither baseline TRAQ domain score predicted transition or time to transition over 3 years of follow up; however there was a trend toward sooner time to transition amongst patients with highest quartile TRAQ scores. This study was limited to evaluating whether transition occurred, and did not address the quality of the transition process, associated cost or patient satisfaction. Validated tools which can provide useful and more comprehensive information about the quality of transition process are certainly needed but not currently available.

In this study, the TRAQ was only tested at baseline and results were not revealed to providers. However, the TRAQ was developed to be used over time with results influencing provider and patient collaboration in the development of self-management and self-advocacy skills. It is possible that change in TRAQ score over time would be more predictive of transition. Another possibility, first proposed by Mackie et al. is that the TRAQ has a "ceiling effect" in which it loses discriminative power in higher scoring individuals [32]. Because it had not yet been fully developed at the onset of this study, the updated TRAQ 5.0 instrument was not used [29].

While we attempted to test the TRAQ in a "realworld" clinical setting, we understand that our findings may not be generalizable. For example, our population was relatively small, largely white (81\%) and nonHispanic (91\%). The age at transfer to adult care was not determined by hospital policy. Individuals up to age 25 years were allowed in the study which and therefore may include some older individuals than would typically be seen at other pediatric outpatient subspecialty clinics. However, $95 \%$ of the subjects in this study were 16 to 21 years of age at enrollment. Additionally it should be noted that TRAQ was ascertained only at a single visit with an adult specialty provider, and longitudinal TRAQ data may be more helpful in predicting when an individual will transition to adult care.

\section{Conclusion}

Our results demonstrate that adolescents and young adults are often not prepared for transition according to recommended guidelines as only half of these 16-23 year olds reported seeing provider independently or discussing transition with provider. Validated transition assessment tools whose use clearly leads to improved outcomes are needed to promote successful transition processes. TRAQ scores did not significantly predict transition or time to transition in this study. More research is needed in larger cohorts to determine optimal methods to evaluate and improve preparedness for transition to adult care in adolescents and young adults with chronic diseases.

\section{Abbreviations}

AAFP: American Association of Family Physicians; AAP: American Academy of Pediatrics; ACP: American College of Physicians; ARHQ: The Agency for Health Care Research and Quality; Gl: gastroenterology; NS-CSHCN: National Survey of Children with Special Health Care Needs; RACER: Readiness for Adult Care in Rheumatology; TRAQ: Transition Readiness Assessment Questionnaire

\section{Acknowledgements}

Not applicable.

\section{Funding}

Funding Sources: This work was supported by the OSU College of Medicine (Roessler) Research Scholarship. Dr. Ardoin's effort on this project was supported by Award Number Grant KL2TR001068 from the National Center for Advancing Translational Sciences. The content is solely the responsibility of the authors and does not necessarily represent the official views of the National Center for Advancing Translational Sciences or the National Institutes of Health.

\section{Availability of data and materials}

The datasets generated and/or analyzed during the current study are not publicly available due inclusion of protected health information but are available from the corresponding author on reasonable request and IRB approval.

\section{Authors' contributions}

PJ performed data analysis and interpretation, assisted with writing, editing and approval of manuscript. GP contributed via data collection, data analysis and interpretation, writing and editing of manuscript, approval of manuscript. SL and CS assisted with data collection, data analysis and interpretation, writing and editing of manuscript, approval of manuscript. JP performed statistical analysis, assisted with writing and editing of manuscript and approved final manuscript. CS assisted with study design, data collection, editing and approving manuscript. GH, BB and MK assisted with data collection, editing and approving manuscript. SA performed study design, data collection, data analysis and interpretation, writing and editing of manuscript, approval of manuscript.

\section{Ethics approval and consent to participate}

Institutional Review Board approval was obtained for this study (Nationwide Children's Hospital IRB10-0026). All participants/legal guardians provided informed consent.

Consent for publication

Not applicable.

Competing interests

The authors declare that they have no competing interests. 


\section{Publisher's Note}

Springer Nature remains neutral with regard to jurisdictional claims in published maps and institutional affiliations.

\section{Author details}

'Division of Rheumatology, Nationwide Children's Hospital, 700 Children's Drive, Columbus, OH 43205, USA. ${ }^{2}$ The Ohio State University College of Medicine, 370 W. 9th Avenue, Columbus, OH 43210, USA. ${ }^{3}$ The Ohio State University Center for Biostatistics, 320 Lincoln Tower, Columbus, OH 43210, USA.

\section{Received: 20 July 2017 Accepted: 23 August 2017}

Published online: 09 September 2017

\section{References}

1. American Academy of Pediatrics, American Academy of Family Physicians, American College of Physicians, Transitions Clinical Report Authoring Group, Cooley WC, Sagerman PJ. Supporting the health care transition from adolescence to adulthood in the medical home. Pediatrics. 2011;128(1):182-200.

2. Crowley R, Wolfe I, Lock K, McKee M. Improving the transition between pediatric and adult healthcare: a systematic review. Arch Dis Child. 2011;96:548-53

3. Wood DL, Sawicki GS, Miller MD, et al. The transition readiness assessment questionnaire (TRAQ): its factor structure, reliability, and validity. Acad Pediatr. 2014;14(4):415-22.

4. Katz J, Mamyrova G, Agarwal S, et al. Parents' perception of self-advocacy of children with myositis: An anonymous online survey. Pediatr Rheumatol Online J. 2011;9(1)

5. Cooley WC. Adolescent health care transition in transition. JAMA Pediatr. 2013;167(7):897-9.

6. McManus MA, Pollack LR, Cooley WC, et al. Current status of transition preparation among youth with special needs in the United States. Pediatrics. 2013:131:1090-7.

7. Chira P, Ronis T, Ardoin S, White P. Transitioning youth with rheumatic conditions: perspectives of pediatric rheumatology providers in the United States and Canada. J Rheumatol. 2014;41(4):768-79.

8. Bollegala N, Brill H, Marshall JK. Resource utilization during pediatric to adult transfer of care in IBD. Crohn's and Colitis. 2013;7(2):55-60.

9. Tuchman L, Schwartz M. Health outcomes associated with transitions from pediatric to adult care. Pediatrics. 2013;132(5):847-53.

10. Pape L, Lämmermühle J, Oldhafer M, Blume C, Weiss R, Ahlenstiel T. Different models of transition to adult care after pediatric kidney transplantation: a comparative study. Pediatr Transplant. 2013;17(6):518-24

11. Committee on Pediatric AIDS. Transitioning HIV-infected youth into adult health care. Pediatrics. 2013;132:192-7.

12. Lotstein DS, Ghandour R, Cash A, McGuire E, Strickland B, Newacheck P. Planning for health care transitions: results from the 2005-2006 national survey of children with special health care needs. Pediatrics. 2009; 123(1):e145-52

13. Lotstein DS, Seid M, Klingensmith $\mathrm{G}$, et al. Transition from pediatric to adult care for youth diagnosed with type 1 diabetes in adolescence. Pediatrics. 2013;131(4):1062-70

14. Yeung E, Kay J, Roosevelt GE, Brandon M, Yerman AT. Lapse of care as a predictor for morbidity in adults with congenital heart disease. Int J Cardiol. 2008;125(1):62-5.

15. American Academy of Pediatrics, American Academy of Family Physicians, American College of Physicians-American Society of Internal Medicine. A consensus statement on health care transitions for young adults with special health care needs. Pediatrics 2002;110(6 Pt 2):1304-1306.

16. Lotstein DS, McPherson M, Strickland B, Newacheck PW. Transition planning for youth with special health care needs: results from the national survey of children with special care needs. Pediatrics. 2005;115(6):1562-8.

17. Prior M, McManus M, White P. Measuring the "triple aim" in transition care: a systematic review. Pediatrics. 2014;134:e1648-61.

18. McPheeters M, Davis A, Lounds Taylor J, Flowers Brown R, Potter S, Epstein R. Transition care for children with special health care needs. Agency for Health Care Research and Quality. 2014;14-EHC027-EF.

19. Klassen AF, Grant C, Barr R, et al. Development and validation of a generic scale for use in transition programmes to measure self-management skills in adolescents with chronic health conditions: the TRANSITION-O. Care, Health and Development: Child; 2014.
20. Ferris ME, Harward DH, Bickford K, et al. A clinical tool to measure the components of health-care transition from pediatric care to adult care: the UNC TRXANSITION scale. Ren Fail. 2012;34(6):744-53.

21. National Health Care Transition Center. Available at www.gottransition.org. Updated December 15, 2015

22. Sawicki GS, Lukens-Bull K, Yin X, et al. Measuring the transition readiness of youth with special healthcare needs: validation of the TRAQ-transition readiness assessment questionnaire. Pediatric Psychology. 2011;36(2):160-71.

23. Mackie AS, Islam S, Magill-Evans J, et al. Healthcare transition for youth with heart disease: a clinical trial. Heart. 2014;100(14):1113-8.

24. Okumura MJ, Ong T, Dawon D, et al. Ten years of improvement innovation in cystic fibrosis care: improving transitions from paediatric to adult cystic fibrosis care: Programme implementation and evaluation. BMJ Qal Saf. 2014 23(Suppl 1):i64-72

25. Zhang LF, Ho JSW, Kennedy SE. A systematic review of the psychometric properties of transition readiness assessment tools in adolescents with chronic disease. BMC Peds. 2014;14(4).

26. Lugasi T, Achille M, Stevenson M. Patients' perspective on factors that facilitate transition from child-centered to adult-centered health care: a theory integrated metasummary of quantitative and qualitative studies. J Adolesc Health. 2011;48:429-40.

27. Stinson J, Kohut SA, Spiegel L, et al. A systemic review of transition readiness and transfer satisfaction measures for adolescents with chronic illness. Int J Adolesc Med Health. 2014:26(2):159-74.

28. Moynihan M, Saewyc E, Whitehouse S, Paone M, McPherson G. Assessing readiness for transition from paediatric to adult health care: revision and psychometric evaluation of the AM I ON TRAC for adult care questionnaire. J Adv Nurs. 2015;71(6):1324-35.

29. Transition Readiness Assessment Questionnaire. Available at: www.etsu.edu/ com/pediatrics/traq. Updated October 10, 2015.

30. Stinson J, Spiegel L, Duffy KW, et al. Develoment and testing of the readiness for adult care in rheumatolgoy (RACER) questionnaire for adolescents with rheumatic conditions. J Adolesc Health. 2012;50(2):S89.

31. Vidal M, Jansa M, Anguita C, et al. Impact of a special therapeutic education programme in patients transferred from a paediatric to an adult diabetes unit. European Diabetes Nursing. 2004;1(1):23-7.

32. Mackie AS, Rempel GR, Islam I, et al. Psychosocial maturity, autonomy, and transition readiness among young adults with congenital heart disease or a heart transplant. Congenit Heart Dis. 2016;11:136-43.

\section{Submit your next manuscript to BioMed Central and we will help you at every step:}

- We accept pre-submission inquiries

- Our selector tool helps you to find the most relevant journal

- We provide round the clock customer support

- Convenient online submission

- Thorough peer review

- Inclusion in PubMed and all major indexing services

- Maximum visibility for your research

Submit your manuscript at www.biomedcentral.com/submit
Biomed Central 